\title{
SUPPLY CHAIN DESIGN
}

\author{
Raza Noman \\ King Abdul Aziz University, Saudi Arabia \\ rnomanahmed@kau.edu.sa
}

Original Scientific Paper
10.5937/jouproman8-27421

\begin{abstract}
In this study, the analysis will be given on "Investigating the role of Knowledge Management in the global supply chain". For the data, collection manufacturing firms is chosen from Pakistan. The method for data collection is secondary data collection. To achieve this, a systematic review is conducted based on qualitative content analysis. The contributions of KM were analyzed through a case study of the Pakistan Dairy company. Further, the case is analyzed by the supply chain process.
\end{abstract}

Keywords: Suppy Chain, Knowledge Management, Supply Chain Process, Organizational Firm, Management Systems.

\section{Introduction}

Knowledge management is an entire systematic approach of an organization aimed at data processing, information usage, and increasing efficiency. Supply from this chain of perspective; Management should be handled with integrated Knowledge management covering analysis and decision making functions. Knowledge improves the ability to do business accurately and on time which is the basic input for the success of businesses (Dalkir, 2017). The main purpose of the SC management is delivering the service to the customer at the lowest cost is effective and efficient information. Knowledge management should work in the light of this information and the supply chain should be kept under central control and transportation, order, production planning, logistics, and operational activities should be carried. Towards changing customer demands the effectiveness of the supply chain is measured by a rapid response. It is activity information management that provides flexibility to this supply chain. Chain members and their integration affect the chain's success and performance by acting as a single company in the supply chain (Santoro, et.al., 2018).

\section{Literature Review}

\subsection{Knowledge Management and SCM}

To develop KM, and fulfill organizational objectives knowledge management involves identifying and analyzing the available and required knowledge. In this context, Natalicchio, et.al., 2017 argue that knowledge management, in addition to managing knowledge assets, also seeks to manage the processes that operate on these assets, broadly covering aspects of development, preservation, use, and sharing of the knowledge, making the organization more efficient and competitive. In order to create new competencies, based on the institutionalization of experiences, knowledge, and expertise, and make it more accessible to the organization, Knowledge management aims to provide adequate knowledge to the right people at the right time, assisting in decision-making and improving the performance of the organizational process (Abubakar, et.al., 2019). 
In seeking to understand the characteristics of the competitive environment of collective and individual needs, Knowledge management has its fundamental principle of human and intellectual capital reflecting the systematic coordination of efforts at the operational and strategic levels (Hussinki, et.al., 2017). To carry out knowledge management, in order to generate organizational effectiveness it is necessary to focus both on the tacit (behavioral) as well as the explicit dimension (structure and technology) (Sharma and Dey, 2018). In order to create a more efficient and effective company, KM represents a deliberate and systematic approach that uses knowledge organizational structure linked to individual skills, competencies, thoughts, innovations, and ideas (Lopes, et.al., 2017).

\subsection{Implementation of Knowledge Management Systems}

$\mathrm{KM}$ can be defined as a representation of rooting, storage, transfer, transformation, application, and protection of knowledge organizational. The concept of Knowledge Management organizational memory, information sharing, and collaborative work are also closely linked (Hislop, Bosua, and Helms, 2018). For the valuation of formalized knowledge such as trademarks or patents through the arrangement of workspaces allowing the exchange of knowledge this Knowledge Management can take very varied organizational forms ranging from the implementation of Knowledge Bases (Obeidat, Al-Suradi, and Tarhini, 2016). However, through the deployment of specific Information Systems that are Management Systems Knowledge (SGC) these approaches are very often implemented. These CMS are defined as Information System classes committed to managing organizational knowledge. That is to say, to support and improve the creation, storage, research and identification, transfer, and integration of knowledge these are technology-based systems information developed (Oliva, et.al., 2019).

\section{The Relationship of Supply Chain and Knowledge Management and Information}

In this context, the strong establishment of supply chain relationships is one of the most difficult aspects of SCM. For this reason, during the design phase of the chain, an information system suitable for the activities of the chain should be developed and information management should be done in line with the objectives (Zhu, et.al., 2017). In two parts the structure of a healthy flow of information should be examined: periodic information and full-time information. Changes in the firm's strategies and policies, price regulation, promotion of new products, and services are included in Periodic information. Periodic information is the entire supply chain, unlike full-time information. It reaches its members periodically. Full-time information flow is realized through an information flow network that all supply chain members are connected to, unlike traditional hierarchical information flow structure. Through this network, all members of the supply chain are directly linked. They can communicate, they can get the information they need full time. Therefore, between customers and suppliers, the increasing degree of communication shows that they are shared. 
The information available to the parties is the most important benefit of integration into the Supply Chain (Kim and Chai, 2017). Manufacturers can transfer market and design information to suppliers and the final distributors can transfer their knowledge and requirements to the suppliers. The vendors provide information on material, price, and quality. In an integrated and dynamic structure, the supply chain should be created, taking into account the strategic partnership. Organizations can evaluate this information through the sharing structure (Qi, et.al., 2017).

\section{Methodology}

In this research paper, a qualitative approach will be used (Kusi-Sarpong, et.al., 2019). For Silverman, 2016 qualitative research means that a social group or an organization. In this approach, the dimensions of reality cannot be measured and focus on understanding and explaining the dynamics of social relationships. It is framed in the same way as bibliographic research tools, relate published references, and discusses academic contributions organizational, information management structures, information systems, and supply chain.

This study will consist of two complementary theoretical perceptions, one is resource-based and the other is knowledge-based innovation (KBI). Therefore, this approach to resource-based (RBV) involves understanding the reasons why certain companies maintain superior performance in the markets in which they operate. The answer will be not only in an adequate competitive position but also that these companies have the resources that are more suited to the demands of these markets. For this reason, the RBV approach sees different companies as both tangible and intangible resource collections, which inevitably lead to different competitive capabilities (Campbell and Park, 2017). On the other hand, knowledge-based innovation is discussed herein in an industrial context. When a creative idea is produced, its transformation into new knowledge depends on a cycle linking the three subsystems and emphasizes the link between idea and knowledge: the creator of the idea, the information field that serves as a reference, and information actors who evaluate, select and validate related ideas. This element encompasses the reversibility of the idea-information link, that is, the transition from knowledge to a creative idea, by promoting an innovation dynamic (from thought to innovation) (Valiollahpur, Aliesmaili, and Hosseinzadeh, 2017). Based on the epistemic connection between the structural analysis of the information contained in the intellectual heritage of the invention and the idea of the invention, which is considered to be a creative knowledge production, we propose a method for generating creative ideas that utilize information (Shujahat, et.al., 2019).

Exploratory research is generally qualitative. For example, the phenomenological method aims to better understand a phenomenon by exploring it in depth. In summary, there is no unique parallelism between exploration and qualitative research, as is between applied research and quantitative research (Awwad, and Akroush, 2016). On the other hand, it is understood that this is a general classification that can guide the understanding of the basic features of the methods of producing knowledge. 
In this research, the role of $\mathrm{KM}$ will be analyzed regarding the case of milk products (Dairy products made from milk, including butter, cheese, ice cream, yogurt, condensed and dried milk) supply chain in Pakistan. In this research, a qualitative methodology is used with a single case study. The justification behind using this research is because it is highly appropriate in terms of context and SCM. This case study also helped in learning a lot about exploratory research. The company chosen has a long history of making dairy products. In this research, an approach related to context analysis was used and in-depth interviews were conducted by company CEO and senior managers. The company was thinking to move it's export their dairy products to the UAE. Each interview conducted also used documentation such as company annual reports and other company-related documents.

\section{Findings and Discussion}

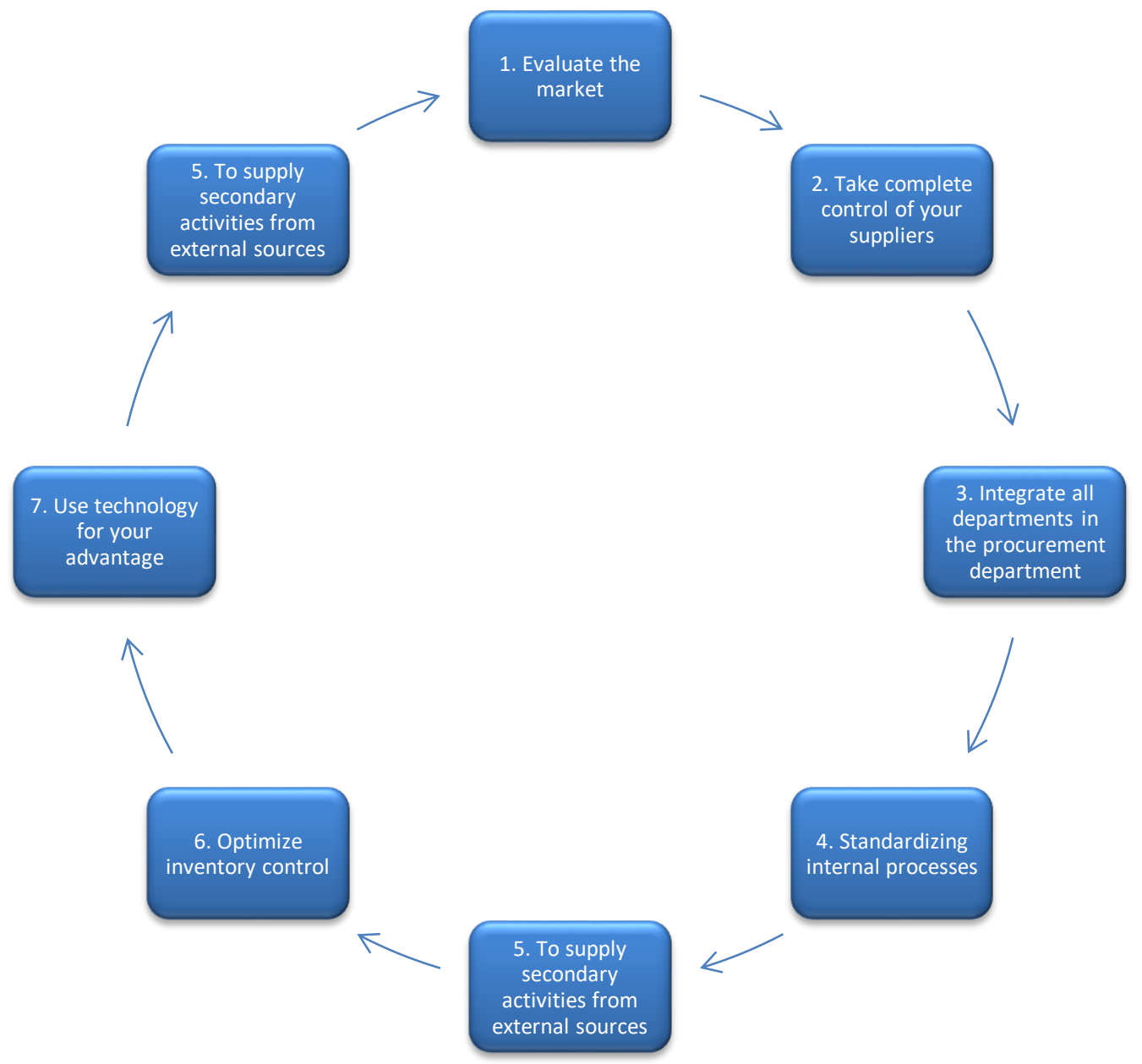

Some steps should be taken into consideration at the time of designing SCM. Each of the steps is related and interconnected to one another. The first step is to evaluate the market. In a company, one of the most effective ways to reduce unnecessary spending and waste resources is to forecast demand, so you can minimize inventory costs. The idea of evaluating the market consists of analyzing the sales history of the business and defining seasonal periods so that it is possible to make accurate projections for future demands. 
In the second step take complete control of your suppliers. Suppliers should be seen as partners in this business. Therefore, the relationship with them should be constantly monitored, in addition to the quality of their products and services, it becomes possible to guarantee the best payment terms and competitive prices (Tseng, et.al., 2018). In the third step integrate all departments in the procurement department. Integrating the various departments of the logistics chain is not just an enthusiasm for managers, but a way to encourage improvements in the company's core business. Therefore, it is important to communicate fluently and know if all employees are up to date on the strategic planning of the business. For example, there is an update of information about the demand forecast. In the fourth step standardizing internal processes takes place the standardizing procedures are one of the safest and most effective ways to encourage improvements in supply chain management, as it enables easier control of processes and data collection (Zimon and Madzík, 2019). In the fifth step to supply secondary activities from external sources. It is very common to encounter companies that try to run all stages of the logistics chain, overload their employees, delay production times, and even affect the quality of the products or services developed. In the sixth step optimize inventory control. Managing the control of goods or raw materials is one of the most important issues in SC management because sales and production may decrease if the stored products reach very low levels, which can lead to loss of supply opportunities in the market. In the seventh step use technology for your advantage. Finally, we could not mention the importance of using a technological tool in the entire optimization of supply chain management. Ultimately, implementing the software that integrates the company's most diverse industries helps control information with efficiency and fluidity (Kianto, Vanhala, and Heilmann, 2016).

\section{Case study: Supply Chain Process in Firm}

In this case, the company that is manufacturing the dairy products was dissatisfied by the local administration and decided to export the daily products. After their decision was made they started to analyze the market by evaluating the above mentioned served SC principles (Boon-Itt, et.al., 2017). In an analysis of the above-mentioned principles, the first step is to evaluate the market of UAE and regarding their demand of milk-related products. The second step is to take complete control of your suppliers for this reason the company should make strategic alliances with the UAE food-related companies. In the third step, it is to integrate all departments so it is necessary to make a strategy of SC in the UAE market. The fourth step is standardizing processes this step is necessary for SC in going to the UAE market as it brings benefits such as increased efficiency, better use of resources, and the quality of your product or service. The fifth step is to analyze the external market so before going to the UAE market it is necessary to analyze the market. In the sixth step the managing and controlling of SC have already been efficiently done in Pakistan so in UAE with new SCM services, this process will not be a problem. So the products that will require a refrigerator such as butter will be provided in order to make SC services efficient. 
In the sixth step, technology is important so the company in Pakistan has already implemented high tech system to monitor its SCM process, and this technology, when applied in UAE SC for delivery of milk products, will also increase companies' efficiency.

After analyzing the full case two were three scenarios that were found.

Scenario 1: Make final products in Pakistani factories and then delivered into UAE in trucks and then to large warehouses in UAE. All information including expiry data of products will be mentioned in the product box. Then these products will be delivered to their respective customers.

Scenario 2: Making raw Products in Pakistani factories. Then delivered the raw products to UAE factories and then packed in UAE as per the demand. No expiry on products as this would help in making long term expiry of products.

After analyzing both of the scenarios it was found that option two was much more favorable. This is mainly due to the reason that the milk products are perishable items they will decompose even some products in just 2 days. So it would be a risk of relying on a new SC management system in a new country. In case if there will be a problem in SC then whole items fully packed will be rotted and they will expire causing huge loss to the company. By making all items to be sealed in UAE with expiry date is much more reasonable because in case there is any problem in SC the products will be stored in huge warehouses and they will only be packed once it will be ready for delivery. The model used for this is Molecular Dynamics (MD). The main reason for using this model is that it is a type of computational molecular simulation that allows the behavior or evolution of a system to be analyzed over time.

\section{Summary}

The main purpose of SCM solutions is to meet the needs of companies involved in the planning, control, and optimization of supply chains. As per the above research, SCM tools rely on the production capacity information available in the company's information system to automatically place order orders typical supply chain include the flow of goods, cost, and planning of goods, needs, deliveries, availability, etc. Information about it is defined through a network of suppliers, manufacturers, distributors, and customers. This approach, which requires a more successful collaboration, allows creating a collaborative environment with strategic suppliers.

\section{References}

Abubakar, A.M., Elrehail, H., Alatailat, M.A. and Elçi, A., (2019). Knowledge management, decision-making style and organizational performance. Journal of Innovation \& Knowledge, 4(2), 104-114.

Awwad, A. and Akroush, M.N., (2016). New product development performance success measures: an exploratory research. EuroMed Journal of Business.

Boon-Itt, S., Wong, C.Y. and Wong, C.W., (2017). Service supply chain management process capabilities: Measurement development. International Journal of Production Economics, 193, 1-11.

Campbell, J.M. and Park, J., (2017). Extending the resource-based view: Effects of strategic orientation toward community on small business performance. Journal of Retailing and Consumer Services, 34, 302-308.

Dalkir, K., (2017). Knowledge management in theory and practice. MIT press. 
Hislop, D., Bosua, R. and Helms, R., (2018). Knowledge management in organizations: A critical introduction. Oxford University Press.

Hussinki, H., Ritala, P., Vanhala, M. and Kianto, A., (2017). Intellectual capital, knowledge management practices and firm performance. Journal of Intellectual Capital.

Kianto, A., Vanhala, M. and Heilmann, P., 2016. The impact of knowledge management on job satisfaction. Journal of knowledge management.

Kim, M. and Chai, S., (2017). The impact of supplier innovativeness, information sharing and strategic sourcing on improving supply chain agility: Global supply chain perspective. International Journal of Production Economics, $187,42-52$.

Kusi-Sarpong, S., Gupta, H. and Sarkis, J., (2019). A supply chain sustainability innovation framework and evaluation methodology. International Journal of Production Research, 57(7), 1990-2008.

Lopes, C.M., Scavarda, A., Hofmeister, L.F., Thomé, A.M.T. and Vaccaro, G.L.R., (2017). An analysis of the interplay between organizational sustainability, knowledge management, and open innovation. Journal of Cleaner Production, 142, 476-488.

Natalicchio, A., Ardito, L., Savino, T. and Albino, V., (2017). Managing knowledge assets for open innovation: a systematic literature review. Journal of Knowledge Management.

Obeidat, B.Y., Al-Suradi, M.M. and Tarhini, A., (2016). The impact of knowledge management on innovation. Management Research Review.

Oliva, F.L., Couto, M.H.G., Santos, R.F. and Bresciani, S., (2019). The integration between knowledge management and dynamic capabilities in agile organizations. Management Decision.

Qi, Y., Huo, B., Wang, Z. and Yeung, H.Y.J., (2017). The impact of operations and supply chain strategies on integration and performance. International Journal of Production Economics, 185, 162-174.

Santoro, G., Vrontis, D., Thrassou, A. and Dezi, L., (2018). The Internet of Things: Building a knowledge management system for open innovation and knowledge management capacity. Technological Forecasting and Social Change, 136, 347-354.

Sharma, R.R.K. and Dey, S., (2018). Managing Tacit and Explicit Knowledge. In International Conference on Management and Information Systems September 21, 22.

Shujahat, M., Sousa, M.J., Hussain, S., Nawaz, F., Wang, M. and Umer, M., (2019). Translating the impact of knowledge management processes into knowledge-based innovation: The neglected and mediating role of knowledge-worker productivity. Journal of Business Research,94, 442-450.

Silverman, D. ed., 2016. Qualitative research. Sage.

Tseng, M.L., Lim, M.K., Wong, W.P., Chen, Y.C. and Zhan, Y., (2018). A framework for evaluating the performance of sustainable service supply chain management under uncertainty. International Journal of Production Economics, 195, 359-372.

Valiollahpur, M. M., Aliesmaili, A. and Hosseinzadeh, B., (2017). Analysis of the relationship between knowledge anagement and innovation in order to offering the knowledgebased innovation model.

Zhu, Q., Krikke, H., Caniëls, M.C. and Wang, Y., (2017). Twin-objective supply chain collaboration to cope with rare but high impact disruptions whilst improving performance. The International Journal of Logistics Management.

Zimon, D. and Madzík, P., (2019). Standardized management systems and risk management in the supply chain. International Journal of Quality \& Reliability Management. 